\title{
Polychlorinated biphenyls in respirable particulate matter from different industrial areas in northern China
}

\author{
Haifeng Nie ${ }^{\mathrm{a}, \mathrm{b}}$, Shan $\mathrm{Fu}^{\mathrm{b}, *}$, Yuan Dong ${ }^{\mathrm{b}}$, Zhongfang Yang ${ }^{\mathrm{a}}$ \\ ${ }^{a}$ School of Earth Sciences and Resources, China University of Geosciences, Beijing 100083, People's Republic of China \\ ${ }^{\mathrm{b}}$ State Key Laboratory of Environmental Chemistry and Ecotoxicology, Research Center for Eco-Environmental Sciences, Chinese Academy of Sciences, Post Office Box 2871, \\ Beijing 100085, People's Republic of China
}

\section{H I G H L I G H T S}

- First report of PCBs detection in PM from Linfen and Datong in China.

- Trichlorobiphenyls were the dominant PCBs in the various media.

- The PCB distributions in $\mathrm{PM}_{2.5}$ and $\mathrm{PM}_{2.5-10}$ were quite different in the two cities.

- Toxic equivalency concentrations based on ten dioxin-like PCBs were reported.

- The major PCB source may be associated with unintentional release of PCBs.

\section{A R T I C L E I N F O}

\section{Article history:}

Received 31 December 2013

Received in revised form 16 April 2014

Accepted 18 April 2014

Available online 20 May 2014

Handling Editor: Gang Yu

\section{Keywords:}

China

Industrial area

Polychlorinated biphenyls

Respirable particulate matter

\begin{abstract}
A B S T R A C T
As two typical industrial bases of China's great metropolises, Lingfen and Datong are affected by the steel industry, chemical plants, coal-fired power plants, and several coking plants, and face pollution from polychlorinated biphenyls (PCBs). Therefore, this study was conducted to determine the PCB concentrations in $\mathrm{PM}_{2.5}$ and $\mathrm{PM}_{2.5-10}$ samples obtained in Lingfen and Datong. We collected 22 respirable particulate matter samples (11 of $\mathrm{PM}_{2.5}$ and 11 of $\mathrm{PM}_{2.5-10}$ ) from Lingfen and Datong, and measured a total of 144 PCB congeners. The total PCB concentrations were $5.92-38.7 \mathrm{pg} \mathrm{m}^{-3}$ (median: $21.58 \mathrm{pg} \mathrm{m}^{-3}$ ) in $\mathrm{PM}_{2.5}$ and $1.83-40.8 \mathrm{pg} \mathrm{m}^{-3}$ (median: $24.3 \mathrm{pg} \mathrm{m}^{-3}$ ) in $\mathrm{PM}_{2.5-10}$ in Linfen, and 4.33-18.5 $\mathrm{pg} \mathrm{m}^{-3}$ (median: $11.9 \mathrm{pg} \mathrm{m}^{-3}$ ) in $\mathrm{PM}_{2.5}$ and $13.0-47.4 \mathrm{pg} \mathrm{m}^{-3}$ (median: $17.4 \mathrm{pg} \mathrm{m}^{-3}$ ) in $\mathrm{PM}_{2.5-10}$ in Datong. Of the $\mathrm{PCB}$ homologues, the dominant PCBs detected in the various media were all trichlorobiphenyls (tri-CBs). Moreover, the $\mathrm{PCB}$ distributions in $\mathrm{PM}_{2.5}$ and $\mathrm{PM}_{2.5-10}$ samples were quite different in the two cities. This may be caused by the differences of the industrial structures, and their relatively unintentional release of PCBs in these cities. Source analysis revealed that the major PCB contaminants in Linfen and Datong were tri-CBs and di-CBs, which were possibly associated with unintentional release of PCBs. Toxic equivalency concentrations based on ten dioxin-like PCBs ranged from $4.0 \times 10^{-5}$ to $2.3 \times 10^{-3}$ pgWHO-TEQ m ${ }^{-3}$ in Linfen, and $4.5 \times 10^{-4}$ to $2.6 \times 10^{-4}$ pgWHO-TEQ $\mathrm{m}^{-3}$ in Datong. The presence of PCB pollution is a potential threat to the residents of Datong and Linfen.
\end{abstract}

() 2014 Elsevier Ltd. All rights reserved.

\section{Introduction}

The potential effects of polluted air on human health has been a hot issue that has triggered numerous investigations in recent years (Mandalakis and Stephanou, 2007; Bartoš et al., 2009; Baek et al., 2011; Sheng et al., 2013). Fine and ultrafine particles can reach lung alveoli in humans (Tasdemir et al., 2004a; Kampa and Castanas, 2008). The inhalation of polluted air is one important

\footnotetext{
* Corresponding author. Tel.: +86 10 62919177; fax: +86 1062923563 .

E-mail address: fushan@rcees.ac.cn (S. Fu).
}

exposure pathway. For example, respirable particulate matter (PM) is the vector by which polychlorinated biphenyls (PCBs) enter the upper respiratory tract. Research results show that air PM and air flow are the main environmental pollutant and migration path, respectively, especially for persistent organic pollutants (POPs) (Kaupp and McLachlan, 1999; Lohmann et al., 2000; Ma et al., 2007).

PCBs are important and widespread POPs in the atmosphere, and because of their persistence, toxicity, bioaccumulation and long-distance migration, they can also be passed on to offspring through the cellular matrix, causing deformities (Priha et al., 
2005). PCBs readily accumulate on particles, and respirable PM have a direct effect on public health, and increase the risk of human exposure to PCBs via inhalation and ingestion (Tasdemir et al., 2004a; Kampa and Castanas, 2008). Thus, PCBs severely threaten human health and ecosystems. PCBs were intentionally produced by industry as technical mixtures for use as the dielectric fluid in transformers and large capacitors, heat transfer fluids and hydraulic fluids (WHO/IPCs, 1993). Although the production and use of PCBs has been banned for many years in China, they are still widespread pollutants in the air, soil, sediments and biota. Most research on environmental contamination from PCBs in China has focused on typical polluted areas such as Taizhou (Han et al., 2010) and Guiyu (Xing et al., 2009). However, the contamination status in urban environments, and especially in industrialized regions, should not be ignored. While there is sufficient data available on the levels of PCBs in soils, sediments and biological tissue (Ren et al., 2007; Wang et al., 2008; Wang et al., 2010), much less is known about its levels in respirable PM, especially in industrialized regions in China. Therefore, it is difficult to estimate the exposure of the population in these regions to PCBs.

In the present study, $\mathrm{PM}_{2.5}$ and $\mathrm{PM}_{2.5-10}$ samples were collected in two typical industrial cities in Shanxi, northern China. There are several potential sources of PCB contamination in the city of Linfen, including iron and steel industries, cement and chemical plants. In contrast, Datong is home to distribution and freight, coal transportion \& sales, coal-fired power plants, paint processing, and several coking plants. Linfen and Datong are not only two of China's great metropolises, but also two types of important industrial bases in China, with populations of approximately 3.4 and 1.1 million urban residents, respectively. Rapid economic growth and urbanization in recent years have sharply aggravated their pollution, and raised a series of related problems. However, the environmental behavior of PCBs in $\mathrm{PM}_{2.5}$ and $\mathrm{PM}_{2.5-10}$ samples of these industrialized areas remains unclear.

Because of the paucity of data on PCB levels of various respirable PM samples from the Chinese industrial environment, we undertook this study to determine both the concentration and profile of PCBs in respirable PM samples from two different types of industrialized areas in Shanxi. The main objectives were to establish the contamination status of each industrial area, explore the interaction of PCBs among $\mathrm{PM}_{2.5}$ and $\mathrm{PM}_{2.5-10}$ samples, and identify possible sources of pollution. The results from this study are discussed to further understand the source, transport and distribution of these contaminants in different industrialized areas.

\section{Materials and methods}

\subsection{Samples}

Linfen is located in southwest Shanxi, China, and covers an area of $20275 \mathrm{~km}^{2}$. The central urban area of Linfen has 3.4 million urban residents. The area has a temperate semi-wet monsoon climate, with a mean annual temperature of $12.2^{\circ} \mathrm{C}$. China clay is the main representative soil type in Linfen. There are many industrial plants within a few kilometers of the urban area of Linfen.

Datong is located in north Shanxi, China, and occupies an area of $14112 \mathrm{~km}^{2}$. The central urban area of Datong has 1.1 million urban residents. The area has a temperate semi-wet monsoon climate, with a mean annual temperature of $5.5^{\circ} \mathrm{C}$. China clay is the main representative soil type in Datong. There are several coal-fired power plants and coking plants around the urban area of Datong.

Sampling sites were set to represent the areas of Linfen and Datong. The sampling locations were chosen using a symmetrical grid (about $25 \mathrm{~km}^{2}$ per grid square), in an attempt to evenly distribute sampling over the region (Fig. 1). According to consider the atmosphere was a more uniform environmental media, one sampling point was selected to represent each corresponding grid. From the corresponding grid for respirable PM samples (sites LF15 and DT1-6) in Linfen and Datong, respectively, 22 respirable PM $\left(\mathrm{PM}_{2.5}\right.$ and $\left.\mathrm{PM}_{2.5-10}\right)$ samples were taken in winter. The detail information of sampling was listed in Table 1.

The PM samples were obtained with a modified medium-volume TH-150 sampler (Wuhan Tianhong Instrument Factory, Wuhan, China) which was a kind of classification sampler. $\mathrm{PM}_{2.5}$ and $\mathrm{PM}_{2.5-10}$ were collected by this sampler in the same period. The overall average volume was approximately $24 \mathrm{~m}^{3}$ (average flow rate: $100 \mathrm{~L} \mathrm{~min}^{-1}$ ) and each sample was a 4 -h composite. The suspended particulate matters were collected onto quartz fiber filters ( $\varnothing 90 \mathrm{~mm}$, Whatman Company, UK). There were $11 \mathrm{PM}_{2.5}$ and 11 $\mathrm{PM}_{2.5-10}$ samples obtained. Before the experiment, the quartz fiber filters were annealed for $4 \mathrm{~h}$ at $550{ }^{\circ} \mathrm{C}$ to remove organic material and equilibrated in desiccators. After sampling, the filters were removed from the inlet, folded in half, returned to pre-cleaned aluminous envelopes and stored at $-18^{\circ} \mathrm{C}$ before analysis.

\subsection{Chemicals}

Five standard solutions of PCB congeners (Accustandard, New Haven, CT, USA) were used to quantify 144 congeners. 2,4,5,6-Tetrachloro- $m$-xylene (TCMX, as a surrogate) was purchased from Supelco (Bellefonte, PA, USA). $n$-Hexane, dichloromethane, and toluene were pesticide grade (Fisher Scientific, Fair Lawn, NJ, USA). Nonane was GC grade (Fluka, Sigma-Aldrich, Munich, Germany). Anhydrous sodium sulfate, sodium hydroxide, silver nitrate, and sulfuric acid were guaranteed reagent grade (Sinopharm Chemical, Beijing, China). Silica gel (60-100 mesh) for chromatography was analytical grade (Qingdao Haiyang Chemical, Qingdao, China). The solvents used were pesticide grade (J.T. Baker, Phillipsburg, NJ, USA).

\subsection{Analysis}

Each PM sample was extracted with $30 \mathrm{~mL}$ of hexane/dichloromethane $(1: 1, \mathrm{vol} / \mathrm{vol})$ by ultrasonication for $4 \mathrm{~min}$ and then centrifuged at $3000 \mathrm{~g}$. This process was repeated three times and the extracts were combined. The concentrated extracts were evaporated to $1 \mathrm{~mL}$ for cleanup. The concentrated extracts were cleaned by using a chromatography column containing the various silica. The PCB fraction was eluted with $100 \mathrm{~mL}$ of hexane. The elution was then evaporated with a rotary evaporator and then reduced to $50 \mu \mathrm{L}$ under a gentle $\mathrm{N}_{2}$ stream for analysis. PCBs were measured with an Agilent 6890 series gas chromatograph (GC) coupled with an Agilent 5973 mass spectrometer (MS) using electron impact ionization source in SIM mode. Gas chromatographic separation was performed on a DB-5MS capillary column ( $30 \mathrm{~m} \times 0.25-\mathrm{mm}$ internal diameter; $0.25-\mu \mathrm{m}$ film thickness). Cleanup and analysis of PCBs followed the modified methods described in our previous report (Fu et al., 2009).

\subsection{Quality control}

A laboratory control group was analyzed to demonstrate lack of interference and cross-contamination. A procedural blank in parallel with each set of six samples was also run to further check for interference and cross-contamination. Method repeatability was examined by regular analysis of duplicate samples (Fu et al., 2009).

An external standard method was used to quantify the concentration of PCBs. The measures taken to ensure the integrity of the results are described in our previous report (Fu et al., 2009). Under optimum conditions, the limit of detection (LOD, signal-to-noise ratio $=3$ ) for samples was in the range of $0.01-0.05 \mathrm{ng} \mathrm{g}^{-1}$ (dry 

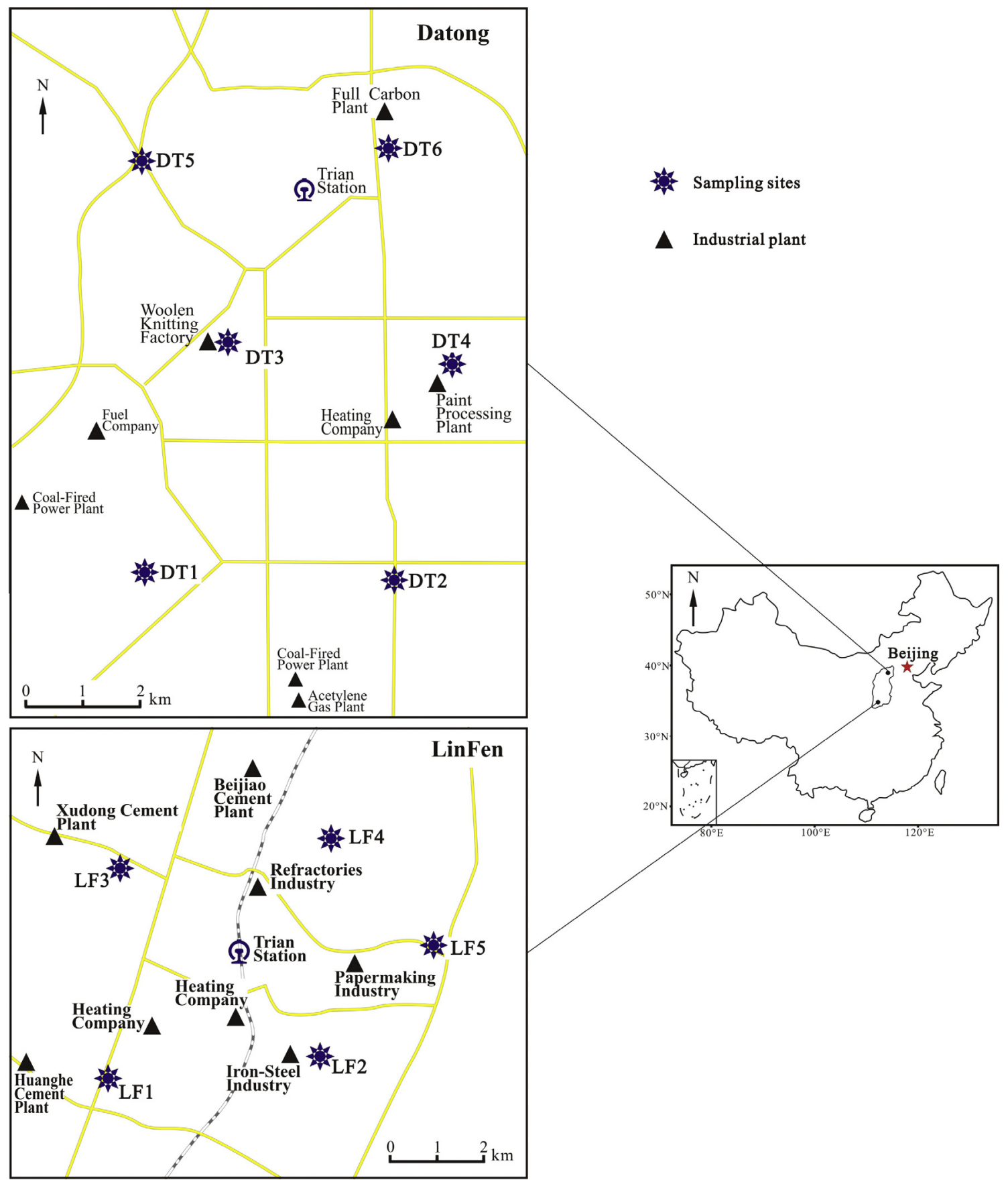

Fig. 1. Sampling sites of respirable PM from Datong and Linfen in northern China.

weight) for PCBs. The matrix spike recoveries for the 144 PCB congeners (including some co-eluting PCB congeners) ranged from 70\% to $110 \%$, with a standard deviation of $15 \%$. The recovery of TCMX surrogate in all samples was within the range of 70-95\%.

A standard reference material sample (GBW 08307, National Research Center for Certified Reference Materials, China) was analyzed to validate the analytical method used. The results were satisfactory, with a $z$ score of $\leqslant 1$ for all congeners (range of $0.02-0.64$ for PCBs; $p<0.05$ ). Recovery of CB-209 surrogate was $85 \%$ with the GBW 08307 sample.

\subsection{Data analysis}

Statistical analysis was performed using PASW statistics 18.0 (IBM, Armonk, NY, USA). We used principal-component analysis
(PCA), a multivariate statistical technique, to derive new principal components (PCs) as a linear combination of the original variables, where PCs attempt to preserve the statistical relationships of the original data. In this study, we investigated interspecies variations in PCB congeners using PCA to deduce the possible sources of PCBs around three industrial sites.

\section{Results and discussion}

\section{1. $P C B$ concentrations in respirable $P M$}

PCBs (144 congeners, including some coeluting PCB congeners) were identified in the 22 respirable PM samples $\left(11\right.$ of $\mathrm{PM}_{2.5}$ and 11 of $\left.\mathrm{PM}_{2.5-10}\right)$ in Lingfen and Datong. The total PCB concentrations 
Table 1

The information of sampling in Datong and Linfen.

\begin{tabular}{|c|c|c|c|c|c|c|c|}
\hline City & Sampling number & Sampling ID & Weather & Air temperature & Wind direction & Wind force & Sampling date \\
\hline \multirow[t]{5}{*}{ Linfen } & LF1 & $\begin{array}{l}\text { LF1-PM2.5 } \\
\text { LF1-PM10 }\end{array}$ & Fine & $-1^{\circ} \mathrm{C} /-10^{\circ} \mathrm{C}$ & No sustained wind direction & Breeze & 4th January, 2012 \\
\hline & LF2 & $\begin{array}{l}\text { LF2-PM2.5 } \\
\text { LF2-PM10 }\end{array}$ & Fine & $2{ }^{\circ} \mathrm{C} /-9{ }^{\circ} \mathrm{C}$ & No sustained wind direction & Breeze & 5th January, 2012 \\
\hline & LF3 & $\begin{array}{l}\text { LF3-PM2.5 } \\
\text { LF3-PM10 }\end{array}$ & Fine & $3^{\circ} \mathrm{C} /-6^{\circ} \mathrm{C}$ & West & Breeze & 6th January, 2012 \\
\hline & LF4 & $\begin{array}{l}\text { LF4-PM2.5 } \\
\text { LF4-PM10 }\end{array}$ & Cloudy & $2^{\circ} \mathrm{C} /-6^{\circ} \mathrm{C}$ & No sustained wind direction & Breeze & 7th January, 2012 \\
\hline & LF5 & $\begin{array}{l}\text { LF5-PM2.5 } \\
\text { LF5-PM10 }\end{array}$ & Cloudy & $4^{\circ} \mathrm{C} /-7^{\circ} \mathrm{C}$ & No sustained wind direction & Breeze & 9th January, 2012 \\
\hline \multirow[t]{6}{*}{ Datong } & DT1 & $\begin{array}{l}\text { DT1-PM2.5 } \\
\text { DT1-PM10 }\end{array}$ & Cloudy & $0{ }^{\circ} \mathrm{C} /-12^{\circ} \mathrm{C}$ & South & Breeze & 15th January, 2012 \\
\hline & DT2 & $\begin{array}{l}\text { DT2-PM2.5 } \\
\text { DT2-PM10 }\end{array}$ & Fine & $-1^{\circ} \mathrm{C} /-16^{\circ} \mathrm{C}$ & Northwester & Breeze & 12th January, 2012 \\
\hline & DT3 & $\begin{array}{l}\text { DT3-PM2.5 } \\
\text { DT3-PM10 }\end{array}$ & Cloudy & $0^{\circ} \mathrm{C} /-14^{\circ} \mathrm{C}$ & South & Breeze & 16th January, 2012 \\
\hline & DT4 & $\begin{array}{l}\text { DT4-PM2.5 } \\
\text { DT4-PM10 }\end{array}$ & Fine & $-2^{\circ} \mathrm{C} /-16^{\circ} \mathrm{C}$ & Northwester & Breeze & 13th January, 2012 \\
\hline & DT5 & $\begin{array}{l}\text { DT5-PM2.5 } \\
\text { DT5-PM10 }\end{array}$ & Cloudy & $-2^{\circ} \mathrm{C} /-15^{\circ} \mathrm{C}$ & Northwester & Breeze & 17th January, 2012 \\
\hline & DT6 & $\begin{array}{l}\text { DT6-PM2.5 } \\
\text { DT6-PM10 }\end{array}$ & Fine & $-1^{\circ} \mathrm{C} /-12^{\circ} \mathrm{C}$ & Northwester & Breeze & 18th January, 2012 \\
\hline
\end{tabular}

Table 2

Total concentrations of PCB homologues in each sample $\left(\mathrm{pg} \mathrm{m}^{-3}\right)$.

\begin{tabular}{|c|c|c|c|c|c|c|c|c|c|c|c|}
\hline Sampling number & Sampling ID & Mono-CBs & Di-CBs & Tri-CBs & Tetra-CBs & Penta-CBs & Hexa-CBs & Hepta-CBs & Octa-CBs & Nona-CBs & $\sum \mathrm{PCBS}$ \\
\hline \multirow[t]{3}{*}{ LF1 } & $\mathrm{PM}_{2.5}$ & N.D. ${ }^{a}$ & N.D. & 12.4 & 7.56 & N.D. & 1.25 & 0.42 & N.D. & N.D. & 21.6 \\
\hline & $\mathrm{PM}_{2.5-10}$ & N.D. & 8.31 & 6.56 & 1.38 & 2.60 & 3.96 & N.D. & 1.46 & N.D. & 24.3 \\
\hline & $\mathrm{PM}_{10}$ & N.D. & 8.31 & 18.9 & 8.94 & 2.60 & 5.21 & 0.42 & 1.46 & N.D. & 45.9 \\
\hline \multirow[t]{3}{*}{ LF2 } & $\mathrm{PM}_{2.5}$ & N.D. & 8.17 & 12.5 & 4.04 & N.D. & 1.83 & N.D. & 0.94 & N.D. & 27.5 \\
\hline & $\mathrm{PM}_{2.5-10}$ & N.D. & 12.1 & 8.85 & 1.17 & 0.58 & N.D. & 0.54 & 2.29 & N.D. & 25.5 \\
\hline & $\mathrm{PM}_{10}$ & N.D. & 20.3 & 21.4 & 5.21 & 0.58 & 1.83 & 0.54 & 3.23 & N.D. & 53.0 \\
\hline \multirow[t]{3}{*}{ LF3 } & $\mathrm{PM}_{2.5}$ & N.D. & 0.48 & 6.31 & 1.58 & 11.8 & 17.9 & N.D. & N.D. & N.D. & 38.1 \\
\hline & $\mathrm{PM}_{2.5-10}$ & N.D. & N.D. & 10.5 & N.D. & 1.63 & 0.50 & N.D. & N.D. & N.D. & 12.7 \\
\hline & $\mathrm{PM}_{10}$ & N.D. & 0.48 & 16.8 & 1.58 & 13.4 & 18.4 & N.D. & N.D. & N.D. & 50.8 \\
\hline \multirow[t]{3}{*}{ LF4 } & $\mathrm{PM}_{2.5}$ & N.D. & N.D. & 8.48 & 6.08 & 3.48 & N.D. & N.D. & N.D. & N.D. & 18.0 \\
\hline & $\mathrm{PM}_{2.5-10}$ & N.D. & 5.21 & 18.9 & 8.17 & 4.98 & 1.25 & N.D. & 2.31 & N.D. & 40.8 \\
\hline & $\mathrm{PM}_{10}$ & N.D. & 5.21 & 27.4 & 14.3 & 8.46 & 1.25 & N.D. & 2.31 & N.D. & 58.8 \\
\hline \multirow[t]{3}{*}{ LF5 } & $\mathrm{PM}_{2.5}$ & N.D. & N.D. & 5.92 & N.D. & N.D. & N.D. & N.D. & N.D. & N.D. & 5.92 \\
\hline & $\mathrm{PM}_{2.5-10}$ & N.D. & N.D. & N.D. & 1.04 & N.D. & N.D. & N.D. & 0.79 & N.D. & 1.83 \\
\hline & $\mathrm{PM}_{10}$ & N.D. & N.D. & 5.92 & 1.04 & N.D. & N.D. & N.D. & 0.79 & N.D. & 7.75 \\
\hline \multirow[t]{3}{*}{ DT1 } & $\mathrm{PM}_{2.5}$ & N.D. & 3.52 & 3.10 & 1.35 & N.D. & 2.35 & 1.23 & 2.04 & N.D. & 13.6 \\
\hline & $\mathrm{PM}_{2.5-10}$ & N.D. & N.D. & 4.29 & 0.63 & 3.10 & 1.48 & 0.50 & 1.25 & 1.77 & 13.0 \\
\hline & $\mathrm{PM}_{10}$ & N.D. & 3.52 & 7.40 & 1.98 & 3.10 & 3.83 & 1.73 & 3.29 & 1.77 & 26.6 \\
\hline \multirow[t]{3}{*}{ DT2 } & $\mathrm{PM}_{2.5}$ & N.D. & N.D. & 8.60 & 0.83 & N.D. & 0.50 & N.D. & N.D. & N.D. & 9.9 \\
\hline & $\mathrm{PM}_{2.5-10}$ & N.D. & 21.9 & 14.7 & 2.50 & 0.75 & N.D. & N.D. & N.D. & N.D. & 39.9 \\
\hline & $\mathrm{PM}_{10}$ & N.D. & 21.9 & 23.3 & 3.33 & 0.75 & 0.50 & N.D. & N.D. & N.D. & 49.8 \\
\hline \multirow[t]{3}{*}{ DT3 } & $\mathrm{PM}_{2.5}$ & N.D. & 3.27 & 9.56 & 4.77 & N.D. & N.D. & N.D. & 0.88 & N.D. & 18.5 \\
\hline & $\mathrm{PM}_{2.5-10}$ & N.D. & 7.10 & 4.60 & 2.48 & 1.85 & 1.67 & 0.65 & N.D. & N.D. & 18.4 \\
\hline & $\mathrm{PM}_{10}$ & N.D. & 10.4 & 14.2 & 7.25 & 1.85 & 1.67 & 0.65 & 0.88 & N.D. & 36.8 \\
\hline \multirow[t]{3}{*}{ DT4 } & $\mathrm{PM}_{2.5}$ & N.D. & N.D. & 8.08 & 0.88 & 0.81 & 0.40 & N.D. & N.D. & N.D. & 10.2 \\
\hline & $\mathrm{PM}_{2.5-10}$ & N.D. & 20.6 & 21.6 & 1.15 & N.D. & 1.21 & 0.60 & 2.25 & N.D. & 47.4 \\
\hline & $\mathrm{PM}_{10}$ & N.D. & 20.6 & 29.7 & 2.02 & 0.81 & 1.60 & 0.60 & 2.25 & N.D. & 57.6 \\
\hline \multirow[t]{3}{*}{ DT5 } & $\mathrm{PM}_{2.5}$ & N.D. & N.D. & 13.3 & 0.81 & N.D. & N.D. & N.D. & N.D. & N.D. & 14.1 \\
\hline & $\mathrm{PM}_{2.5-10}$ & N.D. & 5.31 & 4.69 & 1.46 & N.D. & N.D. & 1.15 & 0.54 & N.D. & 13.2 \\
\hline & $\mathrm{PM}_{10}$ & N.D. & 5.31 & 18.0 & 2.27 & N.D. & N.D. & 1.15 & 0.54 & N.D. & 27.2 \\
\hline \multirow[t]{3}{*}{ DT6 } & $\mathrm{PM}_{2.5}$ & N.D. & N.D. & 1.31 & 1.88 & N.D. & 0.40 & N.D. & 0.75 & N.D. & 4.33 \\
\hline & $\mathrm{PM}_{2.5-10}$ & N.D. & N.D. & 10.9 & 2.92 & 1.85 & 0.67 & N.D. & N.D. & N.D. & 16.4 \\
\hline & $\mathrm{PM}_{10}$ & N.D. & N.D. & 12.2 & 4.79 & 1.85 & 1.06 & N.D. & 0.75 & N.D. & 20.7 \\
\hline
\end{tabular}

${ }^{a}$ N.D. was calculated assuming non-detected measurements were equal to LOD.

(defined as the sum of 144 congeners) were $5.92-38.7 \mathrm{pg} \mathrm{m}^{-3}$ (median: $21.58 \mathrm{pg} \mathrm{m}^{-3}$ ) in $\mathrm{PM}_{2.5}$ and $1.83-40.8 \mathrm{pg} \mathrm{m}^{-3}$ (median: $24.3 \mathrm{pg} \mathrm{m}^{-3}$ ) in $\mathrm{PM}_{2.5-10}$ and $7.75-58.8 \mathrm{pg} \mathrm{m}^{-3}$ (median: $50.8 \mathrm{pg} \mathrm{m}^{-3}$ ) in $\mathrm{PM}_{10}$ samples in Linfen, and $4.33-18.5 \mathrm{pg} \mathrm{m}^{-3}$ (median: $11.9 \mathrm{pg} \mathrm{m}^{-3}$ ) in $\mathrm{PM}_{2.5}$ and $13.0-47.4 \mathrm{pg} \mathrm{m}^{-3}$ (median: $17.4 \mathrm{pg} \mathrm{m}^{-3}$ ) in $\mathrm{PM}_{2.5-10}$ and $20.7-57.6 \mathrm{pg} \mathrm{m}^{-3}$ (median: $32.0 \mathrm{pg} \mathrm{m}^{-3}$ ) in $\mathrm{PM}_{10}$ samples in Datong (Table 2).
In comparison with other areas of China, the median PCB concentrations in the present study were lower than those in the urban area of Beijing $\left(78.7 \mathrm{pg} \mathrm{m}^{-3}\right.$ in $\mathrm{PM}_{2.5}$ and $89.2 \mathrm{pg} \mathrm{m}^{-3}$ in $\mathrm{PM}_{10}$ samples) (Xu et al., 2005), an industrial zone of Taiyuan (46 $\mathrm{pg} \mathrm{m}^{-3}$ in $\mathrm{PM}_{2.5}$ and $49 \mathrm{pg} \mathrm{m}^{-3}$ in $\mathrm{PM}_{10}$ samples) (Fu et al., 2009), and a major e-waste dismantling area in Taizhou (1227 $\pm 433 \mathrm{pg} \mathrm{m}^{-3}$ in $\mathrm{PM}_{2.5}$ samples) (Han et al., 2010). 
Compared with air from other countries, the PCB levels were similar to those in the atmosphere of the Lake Michigan area $20 \pm 15 \mathrm{pg} \mathrm{m}^{-3}$ (Miller et al., 2001). The levels were lower than those in Chicago ( $90 \mathrm{pg} \mathrm{m}^{-3}$ ) (Tasdemir et al., 2004b), a rural site in Melpitz in eastern Germany $\left(110 \pm 80 \mathrm{pg} \mathrm{m}^{-3}\right.$ ) (Mandalakis and Stephanou, 2007), an urban area of Bursa, Turkey $\left(491.8 \pm 189.4 \mathrm{pg} \mathrm{m}^{-3}\right.$ ) (Siddik Cindoruk and Tasdemir, 2007), and wetlands in India (120-320 $\mathrm{pg} \mathrm{m}^{-3}$ ) (Zhang et al., 2008). In contrast, the levels were much higher than those in the Artic (4.9 $\mathrm{pg} \mathrm{m}^{-3}$ ) (Hung et al., 2010), and the Antarctic (12.2 $\mathrm{pg} \mathrm{m}^{-3}$ ) (Baek et al., 2011).

The ratio of highest to lowest concentrations of $\mathrm{PCBs}$ in $\mathrm{PM}_{2.5}$ and $\mathrm{PM}_{2.5-10}$ samples exceeded 3, and obvious regional difference was found in the present study (Table 3 ). The concentrations of PCBs in $\mathrm{PM}_{2.5}$ and $\mathrm{PM}_{2.5-10}$ were no obvious differences in Linfen. However, the concentration of PCBs in $\mathrm{PM}_{2.5-10}$ samples was higher than those in $\mathrm{PM}_{2.5}$ samples in Datong. The distributions of $\Sigma$ PCBs in $\mathrm{PM}_{2.5}$ and $\mathrm{PM}_{2.5-10}$ were shown in Fig. 2. They revealed an increasing trend in $\mathrm{PM}_{2.5-10}$ towards the mideastern area of Datong. On the other hand, there was no significant difference in contamination of $\mathrm{PM}_{2.5}$ and $\mathrm{PM}_{2.5-10}$ in Linfen. In Datong, this might be due to the fact that the coal-fired power plant and heating company were located in the mideastern portion of the city. These results indicated that $\mathrm{PM}_{2.5-10}$ was the most polluted media of PCBs in Datong. Furthermore, the contamination status of $\Sigma$ PCBs might be caused by cement plant and iron-steel industry, which was located in the middle of Linfen. It could be concluded that the PCB distributions in $\mathrm{PM}_{2.5}$ and $\mathrm{PM}_{2.5-10}$ were quite uniform in Linfen. The different typical industries could discharge different sizes of respirable particulate matter. The differences of contamination status should be mainly caused by the different types of industries in these two cities (see Table 3).

\subsection{PCB congener profiles}

In this study, the dominant $\mathrm{PCB}$ in $\mathrm{PM}_{2.5}$ samples were similar to those in $\mathrm{PM}_{2.5-10}$ ones. The dominant PCBs detected in $\mathrm{PM}_{2.5}$ and $\mathrm{PM}_{10}$ samples were trichlorobiphenyls (tri-CBs), with medians of $49 \%$ and $42 \%$ in Linfen and Datong, respectively, followed by diCBs and tetra-CBs ( $\mathrm{CB}$ is chlorobiphenyl), as shown in Fig. 3.
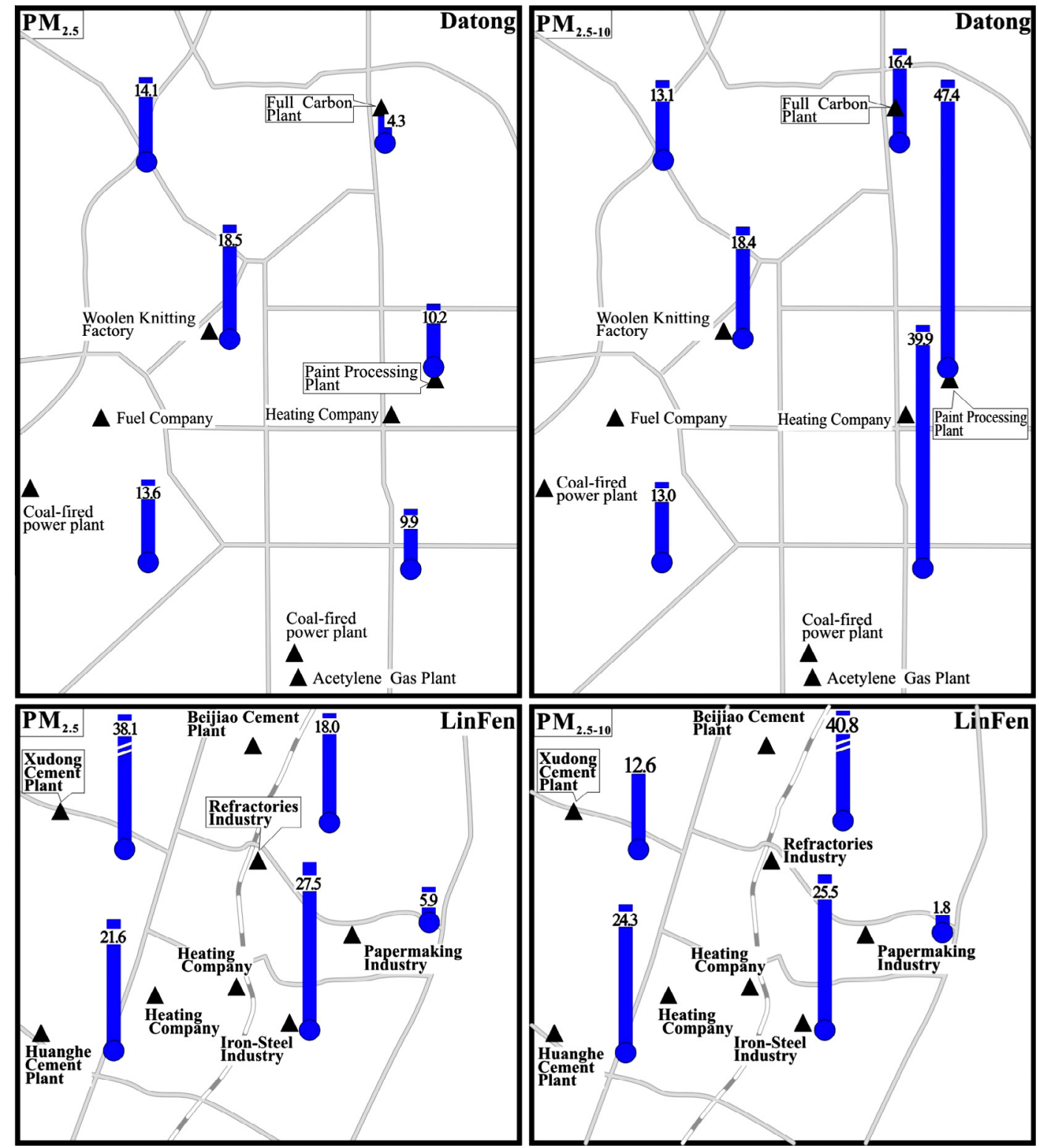

Fig. 2. Distribution of $\Sigma \mathrm{PCBs}$ from various respirable PM samples obtained in Datong and Linfen. 
Higher-chlorinated congeners were detected at relatively low concentrations. This profile was expected because the lower volatility of higher-chlorinated congeners means that they become more firmly bound in heavily polluted areas (Chu et al., 1995). In other areas in China, tri-CBs were also the main PCB homologues detected in air samples (36.03-42.73\%) obtained from the Pearl River Delta close to Guangzhou (Li et al., 2007). In urban air samples measured in Europe, the major PCB congeners were tetra-PCBs and tri-PCBs (Howel, 2007). The above results for Linfen and Datong are reasonable because lower-chlorinated congeners are firmly bound to fine and ultrafine particles owing to their low volatility.

\subsection{Spatial distribution}

There were some spatial distribution characteristics observed for the $\mathrm{PM}_{2.5}$ and $\mathrm{PM}_{2.5-10}$ samples (Fig. 2). The concentration of $\sum$ PCBs from various respirable PM samples showed some difference between Linfen and Datong. No significant differences of the spatial distribution were discovered from $\mathrm{PM}_{2.5}$ and $\mathrm{PM}_{2.5-10}$ samples collected in Linfen. However, the central area was the most polluted region in Linfen. According to $\mathrm{PM}_{2.5}$ samples from Datong, the differences in concentration over the whole city were small. Compared with $\mathrm{PM}_{2.5-10}$ samples obtained in Datong, an obvious increasing trend was found from west to east. These results indicate that in Linfen and Datong, the PCB distributions in $\mathrm{PM}_{2.5}$ and $\mathrm{PM}_{2.5-10}$ samples were quite different. This may be related to the different industrial structures and their relatively unintentional release of PCBs in these cities.

\subsection{Contribution to TEQ}

Because coplanar PCB congeners exhibit toxicological similarity to dioxins, risk assessment of PCBs has aroused great concerns (Giesy and Kannan, 1998). In this study, toxic equivalency (TEQ)

Table 3

Total concentrations of $\mathrm{PCB}$ homologues from $\mathrm{PM}_{2.5}, \mathrm{PM}_{2.5-10}$ and $\mathrm{PM}_{10}$ in Datong and Linfen ( $\mathrm{pg} \mathrm{m}^{-3}$ ).

\begin{tabular}{|c|c|c|c|c|c|c|c|c|c|}
\hline \multirow[t]{2}{*}{ PCBs } & \multicolumn{3}{|c|}{ Linfen $\mathrm{PM}_{2.5}(n=5)$} & \multicolumn{3}{|c|}{ Linfen $\mathrm{PM}_{2.5-10}(n=5)$} & \multicolumn{3}{|c|}{ Linfen $\mathrm{PM}_{10}(n=5)$} \\
\hline & Range & $\operatorname{Ave}^{\mathrm{b}} \pm \mathrm{Sd}^{\mathrm{c}}$ & $\operatorname{Med}^{\mathrm{d}}$ & Range & Ave \pm Sd & Med & Range & Ave \pm Sd & Med \\
\hline Mono-CBs & N.D. ${ }^{\mathrm{a}}$ & - & - & N.D. & - & - & N.D. & - & - \\
\hline Di-CBs & $0-8.17$ & $1.73 \pm 3.6$ & - & $0-12.1$ & $5.13 \pm 5.28$ & 5.21 & $0-20.3$ & $6.85 \pm 8.25$ & 5.21 \\
\hline Tri-CBs & $5.92-12.5$ & $9.12 \pm 3.19$ & 8.48 & $0-18.9$ & $8.96 \pm 6.83$ & 8.85 & $5.92-27.4$ & $18.1 \pm 7.86$ & 18.9 \\
\hline Tetra-CBs & $0-7.56$ & $3.85 \pm 3.11$ & 4.04 & $0-8.17$ & $2.35 \pm 3.29$ & 1.17 & $1.04-14.3$ & $6.2 \pm 5.5$ & 5.21 \\
\hline Penta-CBs & $0-11.8$ & $3.06 \pm 5.12$ & - & $0-4.98$ & $1.96 \pm 1.96$ & 1.63 & $0-13.4$ & $5.02 \pm 5.77$ & 2.60 \\
\hline Hexa-CBs & $0-17.9$ & $4.2 \pm 7.72$ & 1.25 & $0-3.96$ & $1.14 \pm 1.66$ & 0.50 & $0-18.4$ & $5.35 \pm 7.57$ & 1.83 \\
\hline Hepta-CBs & $0-0.42$ & $0.08 \pm 0.19$ & - & $0-0.54$ & $0.11 \pm 0.24$ & - & $0-0.54$ & $0.19 \pm 0.27$ & - \\
\hline Octa-CBs & $0-0.94$ & $0.19 \pm 0.42$ & - & $0-2.31$ & $1.37 \pm 0.99$ & 1.46 & $0-3.23$ & $1.56 \pm 1.26$ & 1.46 \\
\hline Nona-CBs & N.D. & - & - & N.D. & - & - & N.D. & - & - \\
\hline \multirow[t]{3}{*}{$\sum \mathrm{PCBs}$} & $5.92-38.1$ & $22.2 \pm 11.9$ & 21.58 & $1.83-40.8$ & $21.0 \pm 14.7$ & 24.3 & $7.75-58.8$ & $43.3 \pm 20.4$ & 50.8 \\
\hline & \multicolumn{3}{|c|}{ Datong $\mathrm{PM}_{2.5}(n=6)$} & \multicolumn{3}{|c|}{ Datong $\mathrm{PM}_{2.5-10}(n=6)$} & \multicolumn{3}{|c|}{ Datong $\mathrm{PM}_{10}(n=6)$} \\
\hline & Range & Ave \pm Sd & Med & Range & Ave \pm Sd & Med & Range & Ave \pm Sd & $\mathrm{Mec}$ \\
\hline Mono-CBs & N.D. & - & - & N.D. & - & - & N.D. & - & - \\
\hline Di-CBs & $0-3.52$ & $1.13 \pm 1.76$ & - & $0-21.94$ & $9.16 \pm 9.81$ & 6.21 & $0-21.9$ & $10.3 \pm 9.15$ & 7.84 \\
\hline Tri-CBs & $1.31-13.3$ & $7.32 \pm 4.39$ & 8.34 & $4.29-21.6$ & $10.1 \pm 7.03$ & 7.80 & $7.4-29.7$ & $17.5 \pm 8.04$ & 16.1 \\
\hline Tetra-CBs & $0.81-4.77$ & $1.75 \pm 1.54$ & 1.11 & $0.63-2.92$ & $1.85 \pm 0.91$ & 1.97 & $1.98-7.25$ & $3.61 \pm 2.08$ & 2.80 \\
\hline Penta-CBs & N.D..81 & $0.14 \pm 0.33$ & - & $0-3.1$ & $1.26 \pm 1.23$ & 1.30 & $0-3.1$ & $1.4 \pm 1.1$ & 1.33 \\
\hline Hexa-CBs & $0-2.35$ & $0.61 \pm 0.88$ & 0.40 & $0-1.67$ & $0.84 \pm 0.73$ & 0.94 & $0-3.83$ & $1.44 \pm 1.33$ & 1.33 \\
\hline Hepta-CBs & $0-1.23$ & $0.2 \pm 0.5$ & - & $0-1.15$ & $0.48 \pm 0.44$ & 0.55 & $0-1.73$ & $0.69 \pm 0.67$ & 0.63 \\
\hline Octa-CBs & $0-2.04$ & $0.61 \pm 0.81$ & 0.38 & $0-2.25$ & $0.67 \pm 0.92$ & 0.27 & $0-3.29$ & $1.28 \pm 1.23$ & 0.81 \\
\hline Nona-CBs & N.D. & - & - & $0-1.77$ & $0.3 \pm 0.72$ & - & $0-1.77$ & $0.3 \pm 0.72$ & - \\
\hline$\sum \mathrm{PCBs}$ & $4.33-18.5$ & $11.8 \pm 4.8$ & 11.9 & $13.0-47.4$ & $24.7 \pm 15.0$ & 17.4 & $20.7-57.6$ & $36.5 \pm 14.5$ & 32.0 \\
\hline
\end{tabular}

${ }^{\text {a }}$ N.D. was calculated assuming non-detected measurements were equal to LOD.

b Ave was average value.

c Sd was standard deviation.

d Med was median value.

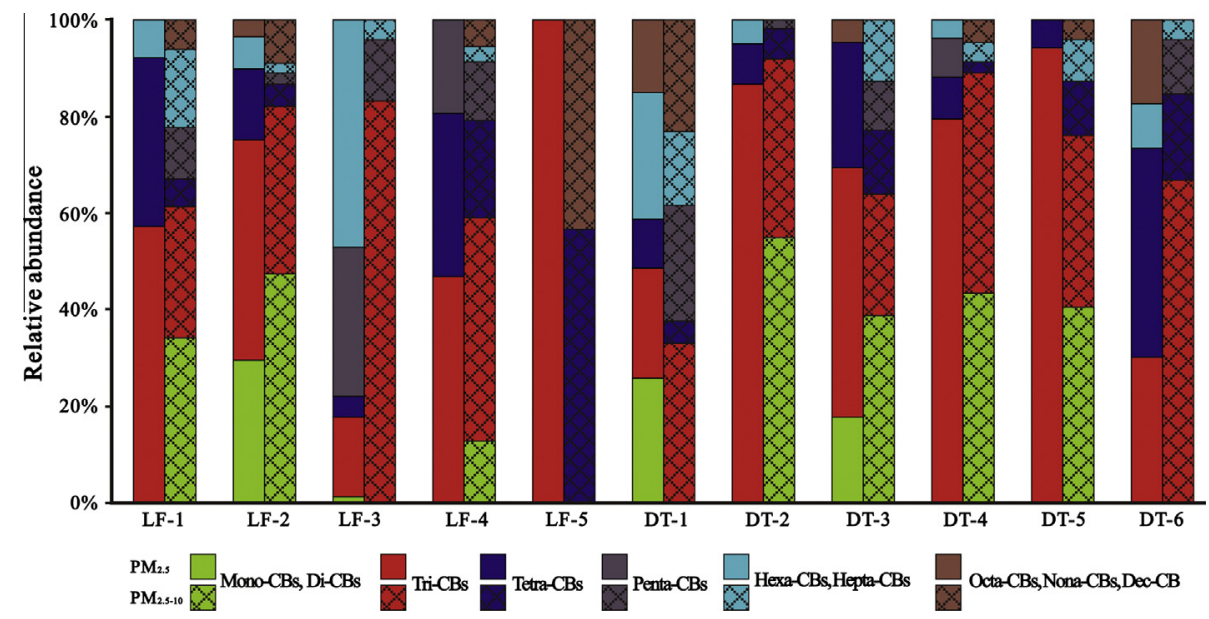

Fig. 3. Distribution of $\mathrm{PCB}$ homologues from respirable PM in Datong and Linfen. 
was determined based on 10 dioxin-like PCBs, PCB-77, PCB-81, PCB-123, PCB-105, PCB-114, PCB-118, PCB-156, PCB-157, PCB167 and $\mathrm{PCB}-189$. These ten dioxin-like PCBs accounted for $6.9 \%$ and $4.5 \%$ of the total of $144 \mathrm{PCBs}$ in $\mathrm{PM}_{10}$ from Linfen and Datong, respectively. In Linfen, PCB-118 (accounting for 50\% of the total TEQ of $\mathrm{PM}_{10}$ ) was the predominant dioxin-like $\mathrm{PCB}$, followed by PCB-156 (accounting for 15\% of the total TEQ of $\mathrm{PM}_{10}$ ). In Datong, PCB-81 (accounting for $21 \%$ of the total TEQ in PM $_{10}$ ) was the predominant dioxin-like PCB, followed by PCB-189 (accounting for $19 \%$ of the total TEQ in $\mathrm{PM}_{10}$ ). Although dioxin-like PCBs was a low proportion of the total PCBs, PCB-81, PCB-118, PCB-156, and PCB-189 were the main contributing analogues.

TEQ concentrations in respirable $\mathrm{PM}_{10}$ (including $\mathrm{PM}_{2.5}$ and $\mathrm{PM}_{2.5-10}$ ) samples were calculated using World Health Organization Toxic Equivalency Factors (WHO-TEFs) (Bhavsar et al., 2008; Van den Berg et al., 2013). In Linfen city, the concentrations of TEQ ranged from $4.0 \times 10^{-5}$ to $2.3 \times 10^{-3} \mathrm{pg}-\mathrm{WHO}$ TEQ $\mathrm{m}^{-3}$ in $\mathrm{PM}_{10}$, N.D. $-1.7 \times 10^{-3}$ pg-WHO TEQ $\mathrm{g}^{-1}$ in $\mathrm{PM}_{2.5}$, N.D. $-1.1 \times 10^{-3} \mathrm{pg}^{-W H O} \mathrm{TEQ} \mathrm{g}^{-1}$ in $\mathrm{PM}_{2.5-10}$, respectively. In Datong, the concentrations of TEQ ranged from $1.5 \times 10^{-4}$ to $8.8 \times 10^{-4}$ pgWHO-TEQ $\mathrm{m}^{-3}$, N.D. $-2.6 \times 10^{-4}$ pg-WHO TEQ $\mathrm{g}^{-1}$ in $\mathrm{PM}_{2.5}$, N.D. $-7.9 \times 10^{-4}$ pg-WHO TEQ ${ }^{-1}$ in $\mathrm{PM}_{2.5-10}$, respectively. These result indicated that the distribution of the TEQ of dioxin-like PCBs in $\mathrm{PM}_{2.5}$ and $\mathrm{PM}_{2.5-10}$ existed obvious differences in Linfen and Datong. $\mathrm{PM}_{2.5}$ was relatively the most polluted media in Linfen. On the other hand, $\mathrm{PM}_{2.5-10}$ was relatively the most polluted media in Datong (Fig. 4). The main emission source of PCBs might be from coal combustion-related processes in Datong and industrial processes in Linfen. It could be concluded that the different emission sources influenced the TEQ distribution of $\mathrm{PCBs}$ in $\mathrm{PM}_{2.5}$ and $\mathrm{PM}_{2.5-10}$.

Regarding total daily intake (TDI), almost $95 \%$ of the total daily intake (TDI) of PCBs is taken up by the food contamination. The inhalation intake doses have been reported to contribute approximately $2.61 \%$ of the TDI (Ministry of the Environment, 2003). Moreover, dioxin-like PCBs were only a part of dioxin-like POPs (such as PCDD/Fs, PBDD/Fs) which also could be found in air, these dioxin-like POPs could also be emitted by industrial and coal combustion-related sources. Because of the lack of data about dioxin-like PCB diet exposure, we cannot provide precise TDIs of dioxin-like PCBs by Datong and Linfen citizens. However, it could be concluded that there was a potential threat of exposure of the urban residents of Datong and Linfen to PCBs.
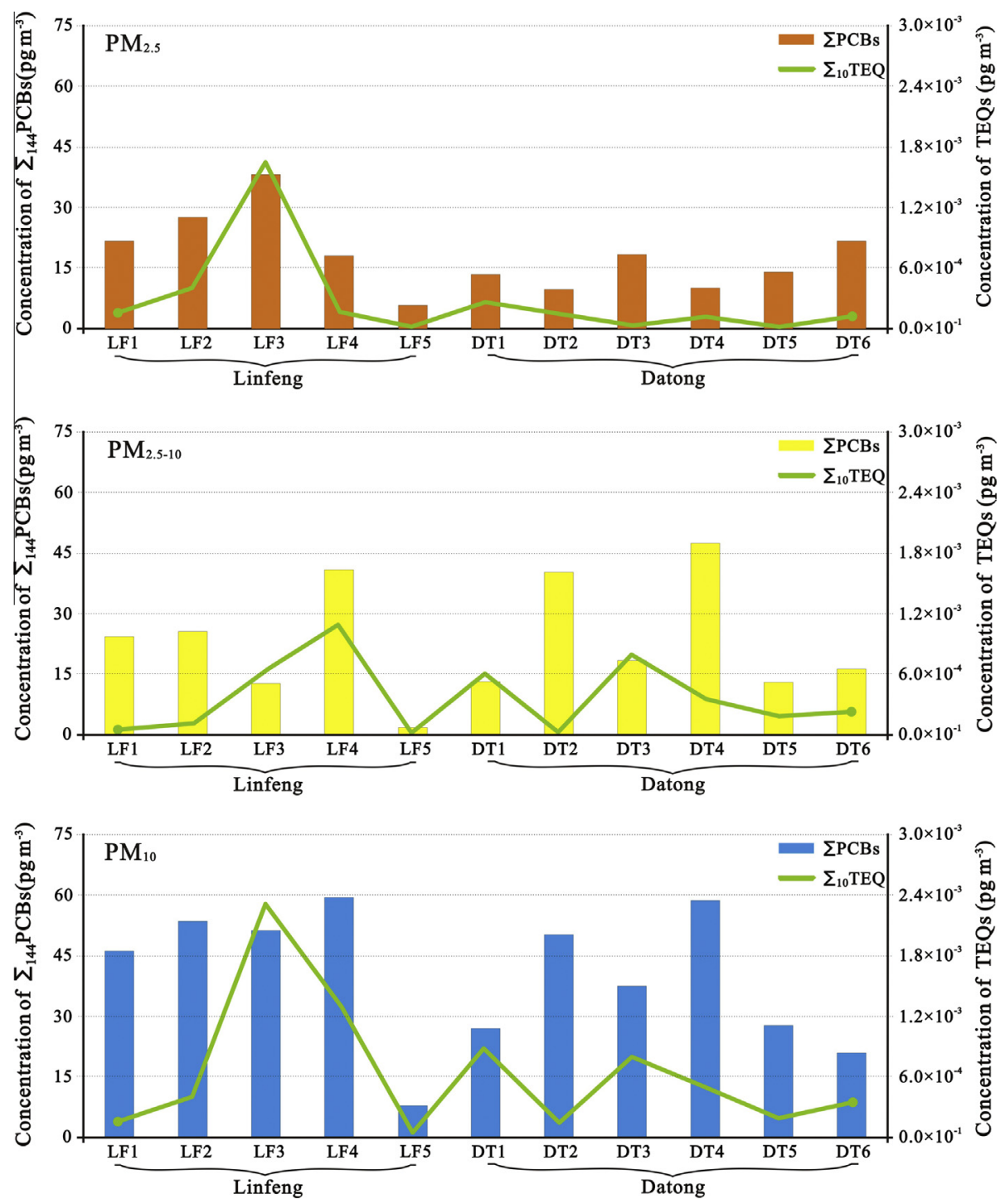

Fig. 4. Total concentrations of PCBs and TEQs in respirable PM from Linfen and Datong. 

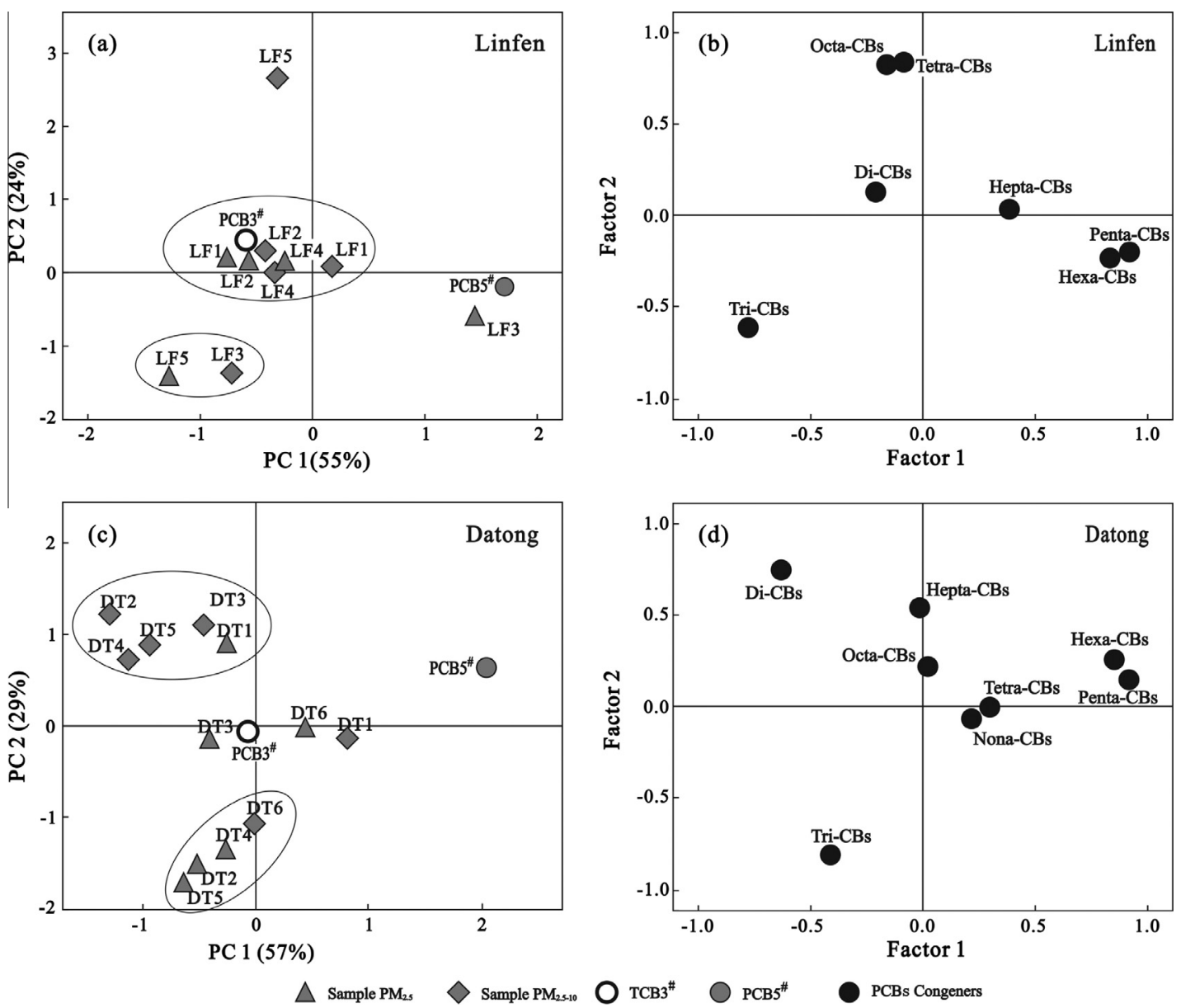

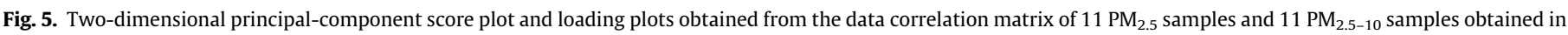
Datong and Linfen.

\subsection{Source analysis}

As a source apportionment method, PCA is a useful approach to elucidate probable source factors of POPs (Kim et al., 2004; Kim and Masunaga, 2005; Mari et al., 2008; Li et al., 2011; Hogarh et al., 2012). To evaluate the profiles of the PCB homologue patterns between $\mathrm{PM}_{2.5}$ and $\mathrm{PM}_{2.5-10}$, we performed PCA on data normalized to percentage of $\Sigma$ PCBs. PCB $3^{\#}$ and PCB $5^{\#}$ samples were also individually normalized to their percentage compositions and then subjected to PCA. Two extracted PCs explained by processing $79 \%$ and $86 \%$ of the data variance in Linfen and Datong, respectively. The loading plots and score plots were obtained after varimax rotation. Component 1 accounted for $55 \%$ and $57 \%$ of the total variance and was characterized by higher-chlorinated homologues, whereas component 2 accounted for $24 \%$ and $29 \%$ was characterized by lower-chlorinated homologues in Linfen and Datong, respectively. The score plot (Fig. 5) indicated that the compositions of PCBs in $\mathrm{PM}_{2.5}$ and $\mathrm{PM}_{2.5-10}$ samples were similar in Linfen and Datong, possibly originating from the same sources. The PCBs found in Linfen could therefore be classified into two main groups that were relatively highly contaminated by tri-CBs and di-CBs. There was also two clear clustering of samples, showing that tri-CBs and di-CBs were the dominant contaminants in Datong It could be concluded that tri-CBs and di-CBs were the dominant contaminants from $\mathrm{PM}_{2.5}$ and $\mathrm{PM}_{2.5-10}$ samples in Linfen and Datong.

In China, approximately $10000 \mathrm{t}$ of PCBs were produced in 1965-1974, $9000 \mathrm{t}$ of trichlorobiphenyl (PCB $3^{\#}$ ) and $1000 \mathrm{t}$ of pentachlorobiphenyl (PCB $5^{\#}$ ) (Xing et al., 2005). PCB $3^{\#}$ mainly used for power capacitor impregnant, its composition is similar to Aroclor1242, PCB $5^{\#}$ was used for paints, insulation materials and other industrial products, its composition is similar with Aroclor1254 in China (Xing et al., 2006). The major homologues produced and used in China was tri-CBs, the major homologue profile of global PCB products was also composed of tri-CBs, and the composition of tri-CBs $(40.4 \%$ of total) was higher in Chinese products than in globally (25.2\% of total) (Breivik et al., 2002). Therefore, tri-CBs should be the dominant PCBs inPM 2.5 and $\mathrm{PM}_{10}$ of Lingfen and Datong. All these samples as well as the major commercial PCB were characterized by a higher proportion of tri-CBs in the $\mathrm{PCB}$ profiles.

Solid fuel combustion, steel production and other industrial processes could produce PCBs and release lower-chlorinated congeners (Lee et al., 2005; Cetin et al., 2007). The different profiles of PCBs between $\mathrm{PM}_{2.5}$ and $\mathrm{PM}_{2.5-10}$ were fully embodied that pollution characteristics in linfen and Datong. According to the highly polluted sampling points in this study, the $\mathrm{PM}_{2.5-10}$ samples obtained from LF4 (near a refractory factory) indicated that levels of di-CBs were relatively high in this points, while those measured for DT6 (located near a full carbon plant) was located in areas with relatively high concentrations of tri-CBs. Moreover, the $\mathrm{PM}_{2.5}$ samples obtained from LF3 (near an cement plant) indicated that levels of penta-CBs were relatively high in this points, while those measured for DT6 (located near a full carbon plant) was located in areas with relatively high concentrations of tri-CBs. It indicated that the sources of PCBs for these sampling locations might be associated with the unintentional release of the different typical industries. 


\section{Conclusions}

The present study was the first to report contamination by PCBs in $\mathrm{PM}_{2.5}$ and $\mathrm{PM}_{2.5-10}$ from different typical industrial cities in China. In general, concentrations of PCBs in this study were lower than those reported in Germany, India, Turky and US. The PCB levels in this study than reported elsewhere might suggest lower polluted status of PCBs in China. However, this was based on 22 samples of Linfen and Datong which might not be representative of the Chinese population overall. Despite this, this study determined both the concentration and profile of $\mathrm{PCBs}$ in respirable $\mathrm{PM}\left(\mathrm{PM}_{2.5}\right.$ and $\left.\mathrm{PM}_{2.5-10}\right)$ samples from Linfen and Datong, explored the interaction of PCBs among different sizes of respirable particulate matter and identify possible sources of pollution. Against this backdrop, the presence of PCB pollution was a potential threat to the residents of Datong and Linfen.

\section{Acknowledgement}

This study was supported by the National Natural Scientific Foundation of China (Nos. 21177148 and 21107122).

\section{References}

Baek, S.Y., Choi, S.D., Chang, Y.S., 2011. Three-year atmospheric monitoring of organochlorine pesticides and polychlorinated biphenyls in polar regions and the South pacific. Environ. Sci. Technol. 45, 4475-4482.

Bartoš, T., Čupr, P., Klánová, J., Holoubek, I., 2009. Which compounds contribute most to elevated airborne exposure and corresponding health risks in the Western Balkans. Environ. Inter. 35, 1066-1071.

Bhavsar, S.P., Reiner, E.J., Hayton, A., Fletcher, R., MacPherson, K., 2008. Converting toxic equivalents (TEQ) of dioxins and dioxin-like compounds in fish from one toxic equivalency factor (TEF) scheme to another. Environ. Inter. 34, 915-921.

Breivik, K., Sweetman, A., Pacyna, J.M., Jones, K.C., 2002. Towards a global historical emission inventory for selected PCB congeners - a mass balance approach 1 . Global production and consumption. Sci. Total Environ. 290, 181-198.

Cetin, B., Yatkin, S., Bayram, A., Odabasi, M., 2007. Ambient concentrations and source apportionment of PCBs and trace elements around an industrial area in Izmir, Turkey. Chemosphere 69, 1267-1277.

Chu, S.G., Yang, C., Xu, X.B., Liu, X.X., 1995. Polychlorinated biphenyl congener residues in sediment and soil from pollution area. China Environ. Sci. 15, 199203.

Fu, S., Cheng, H.X., Liu, Y.H., Yang, Z.Z., Xu, X.B., 2009. Spatial character of polychlorinated biphenyls from soil and respirable particulate matter in Taiyuan, China. Chemosphere 74, 1477-1484.

Giesy, J.P., Kannan, K., 1998. Dioxin-like and non-dioxin-like toxic effects of polychlorinated biphenyls (PCBs): implications for risk assessment. Crit. Rev. Toxicol. 28, 511-569.

Han, W., Feng, J., Gu, Z., Wu, M., Sheng, G., Fu, J., 2010. Polychlorinated biphenyls in the atmosphere of Taizhou, a major e-waste dismantling area in China. J. Environ. Sci. 22, 589-597.

Hogarh, J.N., Seike, N., Kobara, Y., Habib, A., Nam, J.J., Lee, J.S., Li, Q., Liu, X., Li, J. Zhang, G., 2012. Passive air monitoring of PCBs and PCNs across East Asia: a comprehensive congener evaluation for source characterization. Chemosphere 86, 718-726.

Howel, D., 2007. Multivariate data analysis of pollutant profiles: PCB levels across Europe. Chemosphere 67, 1300-1307.

Hung, H., Kallenborn, R., Breivik, K., Su, Y., Brorström-Lundén, E., Olafsdottir, K. Thorlacius, J.M., Leppänen, S., Bossi, R., Skov, H., Manø, S., Patton, G.W., Stern, G., Sverko, E., Fellin, P., 2010. Atmospheric monitoring of organic pollutants in the arctic under the arctic monitoring and assessment programme (AMAP): 19932006. Sci. Total. Environ. 408, 2854-2873.

Kampa, M., Castanas, E., 2008. Human health effects of air pollution. Environ. Pollut. $151,362-367$

Kaupp, H., McLachlan, M.S., 1999. Gas/particle partitioning of PCDD/Fs, PCBs, PCNs and PAHs. Chemosphere 38, 3411-3421.

Kim, K.S., Masunaga, S., 2005. Behavior and source characteristic of PCBs in urban ambient air of Yokohama, Japan. Environ. Pollut. 138, 290-298.
Kim, K.S., Hirai, Y., Kato, M., Urano, K., Masunaga, S., 2004. Detailed PCB congener patterns in incinerator flue gas and commercial PCB formulations (Kanechlor) Chemosphere 55, 539-553.

Lee, R.G., Coleman, P., Jones, J.L., Jones, K.C., Lohmann, R., 2005. Emission factors and importance of PCDD/Fs, PCBs, PCNs, $\mathrm{PAHs}$ and $\mathrm{PM}_{10}$ from the domestic burning of coal and wood in the UK. Environ. Sci. Technol. 39, 1436-1447.

Li, C.L., Hao, Y.M., Mai, B.X., Sheng, G.Y., Fu, J.M., 2007. Spatial distribution of atmospheric PCBs in winter Pearl River Delta. Acta. Sci. Circums. 27, 655-659.

Li, X., Li, Y., Zhang, Q., Wang, P., Yang, H., Jiang, G., Wei, F., 2011. Evaluation of atmospheric sources of PCDD/Fs, PCBs and PBDEs around a steel industrial complex in northeast China using passive air samplers. Chemosphere 84, $957-$ 963.

Lohmann, R., Harner, T., Thomas, G.O., Jones, K.C., 2000. A comparative study of the gas-particle partitioning of PCDD/Fs, PCBs, and PAHs. Environ. Sci. Technol. 34, 4943-4951.

Ma, J., Cheng, J., Xie, H., Hu, X., Li, W., Zhang, J., Yuan, T., Wang, W., 2007. Seasonal and spatial character of PCBs in a chemical industrial zone of Shanghai, China. Environ. Geochem. Health 29, 503-511.

Mandalakis, M., Stephanou, E.G., 2007. Atmospheric concentration characteristics and gas-particle partitioning of PCBs in a rural area of eastern Germany. Environ. Pollut. 147, 211-221.

Mari, M., Nadal, M., Schuhmacher, M., Domingo, J.L., 2008. Monitoring PCDD/Fs, PCBs and metals in the ambient air of an industrial area of Catalonia, Spain. Chemosphere 73, 990-998.

Ministry of the Environment, 2003. Information Brochure Dioxins 2003. Goverment of Japan, Japan.

Miller, S.M., Green, M.L., DePinto, J.V., Hornbuckle, K.C., 2001. Results from the Lake Michigan mass balance study: concentrations and fluxes of atmospheric polychlorinated biphenyls and trans-nonachlor. Environ. Sci. Technol. 35, 278-285.

Priha, E., Hellman, S., Sorvari, J., 2005. PCB contamination from polysulphide sealants in residential areas-exposure and risk assessment. Chemosphere 59 537-543.

Ren, N.Q., Que, M.X., Li, Y.F., Liu, Y., Wang, X.N., Xu, D.D., Sverko, E., Ma, J.M., 2007 Polychlorinated biphenyls in Chinese surface soils. Environ. Sci. Technol. 41 3871-3876.

Sheng, J., Wang, X., Gong, P., Joswiak, D.R., Tian, L., Yao, T., Jones, K.C., 2013. Monsoon driven transport of organochlorine pesticides and polychlorinated biphenyls to the Tibetan plateau: three year atmospheric monitoring study Environ. Sci. Technol. 47, 3199-3208.

Siddik Cindoruk, S., Tasdemir, Y., 2007. Characterization of gas/particle concentrations and partitioning of polychlorinated biphenyls (PCBs) measured in an urban site of Turkey. Environ. Pollut. 148, 325-333.

Tasdemir, Y., Odabasi, M., Vardar, N., Sofuoglu, A., Murphy, T.J., Holsen, T.M., 2004a. Dry deposition fluxes and velocities of polychlorinated biphenyls (PCBs) associated with particles. Atmos. Environ. 38, 2447-2456.

Tasdemir, Y., Vardar, N., Odabasi, M., Holsen, T.M., 2004b. Concentrations and gas particle partitioning of PCBs in Chicago. Environ. Pollut. 131, 35-44.

Van den Berg, M., Denison, M.S., Birnbaum, L.S., DeVito, M.J., Fiedler, H., Falandysz, J., Rose, M., Schrenk, D., Safe, S., Tohyama, C., 2013. Polybrominated dibenzo-pdioxins, dibenzofurans, and biphenyls: inclusion in the toxicity equivalency factor concept for dioxin-like compounds. Toxicol. Sci. 133, 197-208.

Wang, D.G., Yang, M., Jia, H.L., Zhou, L., Li, Y.F., 2008. Levels, distributions and profiles of polychlorinated biphenyls in surface soils of Dalian, China. Chemosphere 73, 38-42.

Wang, Y., Yang, R., Wang, T., Zhang, Q., Li, Y., Jiang, G., 2010. Assessment of polychlorinated biphenyls and polybrominated diphenyl ethers in Tibetan butter. Chemosphere 78, 772-777.

WHO/IPCs, 1993. Polychlorinated Biphenyls and Terphenyls, second ed. Environ. Health Criteria 140.

Xing, G.H., Chan, J.K.Y., Leung, A.O.W., Wu, S.C., Wong, M.H., 2009. Environmental impact and human exposure to PCBs in Guiyu, an electronic waste recycling site in China. Environ. Inter. 35, 76-82.

Xing, Y., Lü, Y., Liu, W., Shi, Y., Luo, W., Ren, H., 2006. Assessment of PCB pollution in spatial distribution and analysis of the $\mathrm{PCB}$ sources in sediments in China. Environ. Sci. 27, 228-234.

Xing, Y., Lu, Y., Dawson, R.W., Shi, Y., Zhang, H., Wang, T., Liu, W., Ren, H., 2005. Aspatial temporal assessment of pollution from PCBs in China. Chemosphere 60, 731-739.

Xu, D., Dan, M., Song, Y., Chai, Z., Zhuang, G., 2005. Concentration characteristics of extractable organohalogens in $\mathrm{PM}_{2.5}$ and $\mathrm{PM}_{10}$ in Beijing, China. Atmos. Environ. 39, 4119-4128.

Zhang, G., Chakraborty, P., Li, J., Sampathkumar, P., Balasubramanian, T., Kathiresan, K., Takahashi, S., Subramanian, A., Tanabe, S., Jones, K.C., 2008. Passive atmospheric sampling of organochlorine pesticides, polychlorinated biphenyls, and polybrominated diphenyl ethers in urban, rural, and wetland sites along the coastal length of India. Environ. Sci. Technol. 42, 8218-8223. 